\title{
IN-COMPETENCIAS DE LA UNIVERSIDAD OCCI-NEO-LIBERAL. DE LOS SUEÑOS DE QUINTILIANO A LAS PESADILLAS DE MICHEL DE MONTAIGNE
}

\section{In-competence of the occi-neo-liberal's university: From the dreams of Quintiliano to the nightmares of Michel de Montaigne}

\author{
Andrés González-NovoA \\ Universidad de La Laguna \\ Correo-e: andala82@hotmail.com
}

Recepción: Is de noviembre de 20I4. Envío a informantes: 20 de noviembre de 2014.

Fecha de aceptación definitiva: Io de enero de 2015

Resumen: Las competencias educativas no están presentes en la literatura pedagógica hasta el Consenso de Washington. Surgen como concepto económico en el pensamiento de los fisiócratas franceses y concretamente en la Riqueza de las Naciones de Adam Smith. Texto donde destaca la asociación del concepto de individuo y de recursos humanos. Este intento por rentabilizar la educación no es nuevo y tiene un interesante precedente en la transición de la República al Imperio romano. Nace el sistema liberal de enseñanza en Las Instituciones Oratorias de Quintiliano y reaparecerá en el Renacimiento mediante los Studium Generale Universitas. Los ensayos de Michel de Montaigne y el callejón sin salida del humanismo nos mostrarán como el Plan Bolonia posee hondas raíces en la memoria de occidente al servicio de los presupuestos de la manufactura, el capitalismo, el liberalismo y, actualmente, de la globalización neoliberal.

Palabras clave: competencias; Quintiliano; Montaigne; universidad.

AвSTRACT: The competences are missing in the pedagogical literature up to the Washington Consensus. They arise as an economic concept in the thinking of the French Physiocrats and specifically in The Wealth of Nations by Adam Smith. Text where it emphasizes the association of the concept of individual and human resources. This attempt to profitable education is not new and has an interesting precedent in the transition from the Republic to the Roman Empire. The liberal educational system is born in the Institutes of Oratory of Quintilian and will 
reappear during the Renaissance through the Studium Generale Universitas. The essays of Michel de Montaigne and the dead end of humanism show us how the Bologna Process has deep roots in the memory of the occident to service the budgets of manufacture, capitalism, liberalism and currently of neoliberal globalization.

KEY WORDs: Competence; Quintilian; Montaigne; university.

$\mathrm{P}$ ODRÍAMOS INTUIR QUE NUESTRA HISTORIA de la Universidad del siglo XXI arranca tras la caída del muro de Berlín, o tal vez, con la famosa sentencia de Thatcher sobre la inexistencia de alternativas, quizás el Consenso de Washington bajo la tutela del FMI, la OCDE y el BM nos dé pistas o puede que el informe PISA y la estrategia de Lisboa nos expliquen qué significa entrar en la sociedad del conocimiento o aclare las intenciones etimológicas de conceptos estandarizados como calidad educativa, competencias, rendimiento académico o eficacia pedagógica.

Lo que parece menos claro es que la Universidad naciese donde la ubican: antes de 1088 y de la fundación de la Universidad de Bolonia ya existía el mundo. Treinta siglos antes en China funcionaba la Escuela Superior de Shang Hjiang, en la India aparece en el siglo vi el centro de estudios budistas Nalanda, Al Karouime en Marruecos en el siglo IX, pero aun antes Constantino II funda la Universidad de Constantinopla..., por no hablar de casos como el centro de estudios religiosos de Machu Pichu, de la Academia de Platón o del Liceo de Aristóteles.

El problema que afrontamos no tiene que ver con analizar o evaluar el concepto de Universidad, sino un modelo de Universidad establecido bajo una educación competencial y a la sombra de un paradigma electroinformático-técnicoeconómico (Moreno, 20I0). Existen otras formulas en situación marginal o en vías de extinción, algunas resisten como elementos poéticos de edades doraras e incluso bordeando los límites de la ciencia-ficción o la superstición, a años luz de los estándares JRC o de las esculturales medidas de los EFQM.

La calidad, etimológicamente, se adscribe a las cualidades que posee un objeto o sujeto, en el caso de la educación, comprende la relación de los aspectos que son sustanciales a lo educativo; sus propiedades inherentes (Vidal Araya, 2007). Complejo y multidimensional análisis que ridículamente termina emparentado con valores unidimensionales como el rendimiento escolar o el índice de citaciones, ambos vinculados perversamente a la ilógica de los números que convierten las minorías en mayorías (Appadurai, 2007).

El neoliberalismo que impregna esta obsesión por la medición y la rentabilidad posee su propia narrativa, un metarrelato no suficientemente criticado ni cuestionado, una odisea occidental que nos aglutina en el desierto de lo real (Baudrillard, 2004), de manera que resulta complejo escapar de su semántica y aun menos de su estructura temporal elíptica (Wallerstein, 20II). La banalidad del presente precisa el abandono, momentáneo, de los neologismos y la búsqueda paciente de los orígenes, que existen, del paradigma que germinó las in-competencias didácticas.

Es curioso que en la totalidad del discurso pedagógico no aparezca la palabra competencia, no exactamente, y que su procedencia se instale en la literatura económica, con mayor precisión, en la obra de Adam Smith. 
IN-COMPETENCIAS DE LA UNIVERSIDAD OCCI-NEO-LIBERAL. DE LOS SUEÑOS DE QUINTILIANO A LAS PESADILLAS DE MICHEL DE MONTAIGNE

ANDRÉS GONZÁLEZ-NOVOA

La riqueza de las naciones, publicada en $\mathbf{1 7 7 6}$, proyecta la teoría de los sentimientos morales de Francis Hutcheson hacia una concepción dinámica e histórica de los sistemas morales, criticando el mercantilismo vertical y situando el motor del bienestar general en el egoísmo particular, idea desarrollada desde el concepto de interés del mismo Hutcheson y que posibilita, peligrosamente, la escisión entre valor de uso y valor de cambio, vital, para la fundamentación del liberalismo y del utilitarismo económico. En el seno de convergencia de ambas esferas ideológicas, en las que habrá de habitar el homo oeconomicus, la división del trabajo será un maquiavélico sistema de selección de talentos y dotación de privilegios y una fórmula matemática que, por medio de la especialización, disminuye -fríamente- los costos de producción de la maquinaria capitalista (Novoa, 2013: 208).

Lo que sí está presente en el desarrollo de los sistemas liberales de educación son los conceptos rendimiento, eficacia, productividad y división social del trabajo. La naturaleza de estos sustantivos nos conduce a sospechar de las intenciones benévolas de procesos de expansión y homogeneización educativa como el EEES y nos permite generar analogías que ofrezcan puntos desde donde mirar los horizontes pedagógicos adscritos a políticas educativas fundamentadas en la oferta (Moreno, 20I0).

Esta idea, en tiempos de globalizaciones y bajo la sombra de las crisis económicas, fagocita los pensamientos existencialistas o religiosos mediante procesos de austeridad y resignación que generan filias privatizadoras y anhelos de acumulación de capital desde las zonas de seguridad o centros de poder, hacia los cinturones de herrumbre o zonas marginales (Wallerstein, 20II). Proceso similar al vivenciado por estoicismo y epicureísmo en los tiempos de expansión imperial romana.

En el presente trabajo, desde el análisis de la Paideia de Jaeger, de la asociación de la cultura al poder, estudiaremos elementos socio-político-pedagógicos de la transición de la República al Imperio romano como preludio al Renacimiento, con el objetivo de oponer dialógicamente las visiones de Quintiliano y Montaigne: las razones y los sinsentidos de esta Universidad de in-competencias certificadas.

El objetivo es trazar vínculos con el proceso de homogeneización educativa desarrollado en el Imperio romano y compararlo con el proyecto de Studium Generale Universitas, precedente histórico del EEES, ambos ejercicios de sistematización en un caso de la Humanitas romana y en el segundo de los studia bumanitatis del Renacimiento.

I. Las Instituciones Oratorias de Quintiliano: la sistematización de la $\mathrm{Hu}$ manitas mediante la extensión didáctica de la Techné. Un preludio de la estandarización y la burocratización de los fines de la educación

Los elementos cuantificables y objetivables del paso de la República al Imperio $^{\mathrm{I}}$ son la demografía y los movimientos migratorios. Dichos factores, bajo el

En Grecia el mismo proceso lo podemos entender de la polis de Pericles y Platón a la oikoumene aristotélica y alejandrina. 
control político y militar, adscritos a las limitaciones de las tecnologías del transporte y el conocimiento de la geografía, describen con precisión lo que el historiador Arnold Toynbee definiera como Estado Universal, es decir, aquel período civilizatorio en el cual el mundo conocido es y está conquistado.

Las reflexiones de James Bowen, Werner Jaeger, Gordon Childe, Chester Starr, Fustel de Coulanges y Henri-Irené Marrou (entre muchas) sugieren que durante el tránsito de las sociedades arcaicas a las polis (ciudades-estado) se originan, al mismo tiempo, elementos políticos, económicos y militares propios de los sistemas esclavistas de producción y elementos filosóficos, poéticos y científicos críticos con dichos sistemas ${ }^{2}$. En el cruce de caminos se establece estructuralmente un sistema de enseñanza (que entenderemos como tradicional) que sueña con una ciudadanía fiel a los intereses de la polis. En términos marxistas, esta superestructura aristocrática (sistema tradicional de enseñanza) servirá de modelo en momentos de crisis (a través de la idealización romántica del espacio escénico del ágora), para ilustrar un imaginario o utópico lugar donde todos los ciudadanos se exponen ante sus iguales.

En la época de esplendor ateniense y en los tiempos republicanos de Cicerón se escriben (se inventan, se imaginan, se proyectan) historias que desde un prisma $\mathrm{u}$ otro perciben al hombre profundamente respetuoso con el mundo, y consigo mismo.

Son períodos de apogeo de la Paideia o de la Humanitas que generan excedentes tanto materiales como espirituales. Ambos factores favorecen al «empresario ${ }^{3}$ que comprende, inmediatamente, que conquistar el mundo no es solamente conocerlo, sino hacerlo irreconocible a los demás. El héroe homérico, el artesano de Hesíodo, la kalokagathia y la polis se deshacen como visión teórico-filosófica y política bajo el artificio militar, comercial y administrativo del Imperio.

Cabe pensar que el problema esencial habita en el surgimiento del sistema liberal de enseñanza y en su arbitrario antagonismo con el sistema tradicional. Pues tanto en el helenismo como en el Imperio, el cambio del ágora por el circo muestra la necesidad y el resultado de un modelo de ciudadanía ajeno a los viejos valores de responsabilidad y sacrificio que tanto defendieron Sócrates (470-377 a. C.) mirando a la kalokagathia y Marco Porcio Catón (234-I49 a. C.) en defensa de la Roma arcaica.

Si buscamos el paso de la República al Imperio y lo entendemos en el contexto toynbeeano del Período de Perturbaciones al Estado Universal, podemos

2 Tanto en el período democrático de Pericles como en la República romana-que entroncamos en el período de perturbaciones de ambas civilizaciones- Sócrates por un lado y Séneca por el otro representan el pensamiento del hombre dentro de una sociedad sostenible. En cambio, en el período helenístico y en el del Imperio surgen paradigmas de pensamiento del hombre soportando la esclavitud. Son dicho ejercicio de emancipación ante el horror el pensamiento existencialista, el cinismo, el epicureísmo, el estoicismo y el pesimismo.

Usamos el concepto desde su raíz. Una clase que se propicia desde antiguas monarquías que en expansión requieren de funcionarios, dicha expansión favorece la aparición de emprendedores que generen procesos comerciales y con ello acumulan riqueza y con ella la necesidad de mayores cotas de poder. Sean mercaderes, banqueros, prestamistas o juristas. Gremios que configurarán el espíritu de la burguesía del xviII. 
IN-COMPETENCIAS DE LA UNIVERSIDAD OCCI-NEO-LIBERAL. DE LOS SUEÑOS DE QUINTILIANO A LAS PESADILLAS DE MICHEL DE MONTAIGNE

ANDRÉS GONZÁLEZ-NOVOA

encontrar que la areté política griega -que representa por antonomasia el ideal democrático de convivencia- se ha quedado inservible -no obsoleta- en el mundo conocido.

Volviendo a Werner Jaeger y entendiendo como la primera escuela la que nace para conservar el poder a través de la tradición y la segunda la que brota de las ansias de los nuevos candidatos de usurparlo, podemos deducir que la situación que van a ofrecer el helenismo, el Imperio, el cristianismo, el absolutismo y la globalización son la magnificación instrumental de los sistemas esclavistas de producción a escala global4.

Una sociedad como la romana, que desde su época arcaica demuestra una profunda pasión por la techné, necesita una estructura administrativa, política y educativa eficaz que sistematice, ordene, gestione y ejecute todas las ideas del pasado para rentabilizarlas (salvando las distancias, este discurso no difiere en exceso de las intenciones del EEES y de las actuales políticas de calidad de la educación).

En dicho contexto no son interesantes los ciudadanos críticos, ni las vitalidades existencialistas, son más útiles individuos infantilizados y consumistas, formados instrumentalmente para ejecutar órdenes y orientados desde un sistema de instrucción pública a ser esclavos de sus pasiones. Justo lo contrario que forjó el mismo estoicismo que hizo sólidas las vísceras del Imperio. Sin duda, el ciudadano imperial no tiene nada que ver con el orador republicano.

En el momento en el que el sistema se expande y configura el proyecto civilizatorio del imperio's, se toman decisiones que resultan interesante describir y analizar:

- Los procesos colonizadores y las victorias militares son insuficientes sin los poderosos procesos de aculturación. Para ello es fundamental la configuración de una idea de cultura universalizable que pueda ser expandida al servicio del Imperio. (Actualmente, la sociedad de la información que emana del Tratado de Lisboa o del Consenso de Washington).

- La Humanitas romana -la transmutación de la Paideia griega- va a sufrir la tiranía y absolutización de la techné. Se va a instrumentalizar y ahí es donde se convierte en fundamental Quintiliano.

- Roma aniquila la resistencia de la mos maiorum y abre las puertas al helenismo. Los paradigmas existencialistas corrosivos para el sistema son tornados en táctica del othium. En ese espacio pierden toda su capacidad de impacto.

- Quintiliano en las Instituciones Oratorias desvela con claridad el proceso de instrumentalización del estoicismo y funda un pre-naturalismo que se convertirá en la superestructura educativa del Imperio.

4 Período retratado por la ausencia de idea originales, la sistematización, el desarrollo geométrico de la techné, el consumismo, las drogas, el individualismo psicologizante, el opio para el pueblo, la «guetización» del pensamiento alternativo, el fundamentalismo, el terrorismo, la extensión virtual de la globalización a través del pensamiento uniforme.

En palabras llanas lo intuimos como un ancestral intento de unir la cuenca del Mediterráneo -algo que también pretendió el helenismo y las conquistas de Alejandro Magno-, un proyecto recurrente que podríamos y haremos recorrer por los siglos para encontrarlo como una constante. Lo que hoy es la Unión Europea ya fue en el imperio la oikoumene. 
- La base del Imperio es la creencia de que los ciudadanos deben ser obedientes, poseer buena memoria para poder imitar los modelos hegemónicos, ser débiles para tener miedo a las instituciones y resultar cuantitativamente productivos. En Quintiliano y en la estructuración del Imperio se integran: la versión esencialista del héroe homérico con la transmutación en esclavo del artesano de Hesíodo para la estetización de la kalokagatbia, y la instrumentalización de los espacios democráticos. Todo ello vertebrado desde un estoicismo prenaturalista que acuñará, como moneda oficial, al esclavo instruido.

- La concepción del mundo como un cuerpo del estoicismo se ajusta al engranaje de la máquina imperial y ofrece analogías con el discurso totalizador de la globalización del siglo xxI.

Entender cómo Quintiliano, a través de su obra tecno-didáctica, favorece un proceso de globalización que fracasa en su objetivo de humanizar a la humanidad es fundamental para, en el actual período de globalización y a través de la educación, orientarse hacia el desarrollo de una ciudadanía uniformada (Bayly, 2004). Conocer el pasado y nutrirse de la tradición posibilitadora ofrece en ocasiones la oportunidad a una generación de inventarse sus propios errores.

Quintiliano no es ajeno al contexto cultural del Imperio que, como bien explican Marrou, Bowen, Gibbon, Kramer, Starr, Coulanges y Belenguer Calpe, es un espacio histórico de sistematización, categorización, ordenamiento y almacenamiento de información. Estas características están claramente presentes en los criterios de acreditación de la ANECA, de acuerdo con las previsiones de la Ley Orgánica 6/200I de Universidades.

Veamos qué se entiende desde la herencia del helenismo - del cual también proviene el estoicismo- por enciclopedismo. Pues en su aspiración a forjar al modelo del orador perfecto afirma de tal manera:

Porque también los que forman a un hombre sabio, de modo que sea en todo consumado, y (como dicen) un Dios en la tierra, no solamente pretenden instruirle en todo lo celestial y humano, sino que le van también guiando por ciertas menudencias (si las miramos en sí mismas), hasta enseñarles ciertos modos de argüir con falacia la más disimulada: no porque estos argumentos falaces, y que llaman de crocodilo puedan constituir al hombre sabio, sino porque éste debe saber hasta las cosas más menudas (Quintiliano, I916, 45).

Estas cosas menudas a las que atiende están al servicio de la astucia, no de la virtud o de la honestidad, lo cual puede hacernos entender cómo la acumulación de información no provee a una civilización de criterios de convivencia democrática sino que sirve de jungla conceptual para que las clases dominantes, es decir, los más fuertes, puedan, a través de las concreciones históricas de la bumanitas romana, obtener ventaja a través de la debilitación de las masas desde la instrumentalización de las ciencias y las artes. El enciclopedismo diseña la arquitectura administrativa de la cultura para la dogmatización de la misma, desde la asociación y el control directo por parte de los estamentos imperiales de 
IN-COMPETENCIAS DE LA UNIVERSIDAD OCCI-NEO-LIBERAL. DE LOS SUEÑOS DE QUINTILIANO A LAS PESADILLAS DE MICHEL DE MONTAIGNE

ANDRÉS GONZÁLEZ-NOVOA

la superestructura educativa. Lo que hoy, con más de veinte siglos de distancia, hacen los indicadores de impacto de las revistas científicas.

Esta codificación, ordenación, selección y difusión cultural va a requerir de varios elementos que podemos entender propios de la techné educativa, entre los que lucen como narcisos mitológicos: la concepción finalista de la retórica como arte práctica, la definición de arte como imitación, la reconversión de la historia en un compendio de «lugares comunes» y la estructuración emergente del puericentrismo como preludio del naturalismo pedagógico. Todo ello, favoreció la conversión del arte en experiencia y del sistema educativo multidisciplinar en maquiavélico telar de una hereditaria división social del trabajo.

Quintiliano describe en el capítulo xix del segundo libro que existen tres tipos de facultades o ciencias. Las facultades teóricas que se basan en la especulación y el conocimiento de las cosas, las facultades prácticas que son la obra y ejecución de una cosa y las facultades de imitación, entre las cuales se encuentra el arte. El hispano-romano en su labor de enciclopedista multidisciplinar y con el fin de dotar de eficacia a la futura administración imperial, va a considerar que la retórica sea un híbrido de las dos últimas facultades como así expresa: «Según esto debemos decir que la retórica es arte práctica, pues ella perfecciona la obra en que se emplea, lo que ninguno ha negado hasta ahora» (Quintiliano, I27). Y hablamos de funcionalidad, rendimiento y economía porque el Imperio necesita urgentemente una administración eficaz para enfrentarse a una creciente crisis, producto de su incapacidad real de extender la idea de Roma entre la barbarie.

Por ello, sin duda, no puede permitirse perder el tiempo como Jean Jacques $\mathrm{y}$, aun cuando desee defender y extender la bumanitas ciceroniana, no le queda otra opción que enhebrar lo deseable con lo necesario. Para ello el tecno-didacta convertirá al othium en su Quimera y la multidisciplinariedad en su Belerofonte. En una defensa del khrónos frente al kairos, las Instituciones Oratorias muestran, con preocupación, la cuestión del tiempo en el aprendizaje y un profundo interés en las características psicológicas del niño: «Prueba de esto es, que sin que se les apriete a los niños, en dos años, luego que comienza a pronunciar bien, hablan de todo; pero los esclavos recién comprados ¿cuántos años gasta, y cuánta repugnancia no les cuesta aprender el latín?» (Quintiliano, 63).

Para ello, la descontextualización de la Historia ${ }^{6}$-a la que considera única fuente de verdad-, como atajo a través de los «lugares comunes», proporcionará soluciones a corto plazo para resolver el conflicto tradición-modernidad, un proceso que integrará en el plan de estudios guiado por la multidisciplinariedad como elemento de alto rendimiento a través de la motivación; el juego; la competición; el aprendizaje significativo, y un elemento a estudiar con atención: la supresión del castigo y su sustitución por el refuerzo positivo.

El castigo que, en la línea estudiada desde los griegos hasta el hispano-romano, venía bien considerado, en el umbral marcado por la figura de Crisipo de Soli, sufre una profunda crisis metodológica. En tiempos de Tito Flavio Domiciano

6 Sería interesante entender que la memoria que es la capacidad fundamental sobre la que articula su obra Quintiliano es un concepto enciclopédico, cuantitativo, más cercano al almacenamiento que a la profundización del mismo, a lo que Confucio llamó Sabiduría. 
se han desarrollado en el seno del cosmopolitismo sucesos que preocupan a los ciudadanos del Imperio. El crecimiento demográfico y los movimientos migratorios han acelerado los procesos de emancipación de los esclavos; ello fundaría corrientes ideológicas cercanas a los movimientos existencialistas del helenismo que, dentro del naciente cristianismo, encontrarán lugar propicio de acogida.

Dichas filosofías que heredan genotipos del estoicismo ${ }^{7}$ y del epicureísmo son altamente peligrosas frente a estados de autoridad explícita. Los propios ciudadanos no suponen tanto poder y respeto sobre los esclavos como antaño, los actos de rebelión y violencia se han extendido por las grandes ciudades y entre importantes familias; lo que hace que la astucia, propia de la areté imperial, prevalezca. Para Quintiliano eliminar el castigo es practicar sutiles maniobras o tácticas para la domesticación y la fidelización, sin la necesidad de crear antagonistas. Así que en concordancia a considerar la pereza como anti-sistema, será de vital importancia extender el modelo de instrucción público para transformar el concepto de esclavo-mártir, que discurre de los patios a las catacumbas, en el de esclavo-instruido con salario imperial.

El descrédito de los sistemas filosóficos, a través de lo estético y contemplativo, va a poner fin a las visiones teórico-políticas y filosóficas con la integración de dichas abstracciones en el utilitarismo de una virtud rentable -entendida como la aceleración de los procesos de socialización-. Bien ilustrado este hecho histórico y para dar por concluidas las aportaciones de Quintiliano al Naturalismo Pedagógico y al concepto de Modernidad recogido en la figura de Michel de Montaigne, es preciso explicar con detalle el «qué» quiere y el «cómo»:

- El «qué»: la esencialización del estoicismo para la vertebración de la superestructura educativa al servicio del Imperio.

- El «cómo»: un sistema educativo público pre-naturalista para la capacitación y competencia (arte y experiencia) de un cuerpo de administración pública (división social del trabajo), para la gestión del mundo conquistado.

El Imperio romano y el Renacimiento, atravesando el inmenso océano medieval, ofrecerán a Montaigne la posibilidad de rescatar la todavía valiosa obra del hispano-romano:

- La transmutación del arte de contener y del arte contemplativo de la polis al arte expansivo y fáctico del Imperio.

- Las guerras civiles, la transición graciana y la Pax Romana de Augusto nacen de un proceso de homogeneización unilateral que aniquila cualquier espacio de resistencia de identidades.

- Los procesos de urbanización del Imperio generan unos ingentes perímetros de herrumbre, in-habitables, habitados por mano de obra barata o esclavos.

- La crisis del Imperio será comercial, pero sobre todo administrativa.

La exotización de la oikoumene es un proceso que se genera desde las metrópolis en relación con lo bárbaro o producto de la barbarie. Una visión etnocentrista del mundo que simplifica las otras culturas y desde la homogenización violenta se apropia de las analogías y demoniza las contradicciones. El lenguaje rico y variado se va simplificando a favor o en aras de una comunicación global conformándose en correcta y estética en tanto vacía y neutra. 
IN-COMPETENCIAS DE LA UNIVERSIDAD OCCI-NEO-LIBERAL. DE LOS SUEÑOS DE QUINTILIANO A LAS PESADILLAS DE MICHEL DE MONTAIGNE ANDRÉS GONZÁLEZ-NOVOA

Por dichos aspectos Quintiliano, como funcionario, va a luchar por mantener el status quo de su clase social -gramáticos y retóricos- a través del pre-naturalismo y con la artificialización del estoicismo. La educación pública será, con el beneplácito de Vespasiano (9-79 d. C.), la nueva maquinaria para modernizar el régimen hereditario y vestirlo de movilidad social.

Para ello el materialismo mecanicista de los atomistas servirá de esqueleto del Imperio como orden lógico y eficaz; y el panteísmo vitalista del estoicismo, para la vertebración de la superestructura educativa en la medida que el mismo Imperio, divinizado, es incuestionable. Como bien expresa Enrique Belenguer (2004: 22): «La gran razón a la que no se puede llegar por parte del pueblo». Algo muy similar ocurre, salvando las distancias, con el arte de Tomás de Aquino y su traducción de la escolástica aristotélica.

Observemos en las propias palabras del hispano-romano cómo percibe las influencias helénicas en clave de amenaza y decadencia para la gloria del Imperio:

Pero por cuanto abandonamos los estudios de la sabiduría por aquellos que se dedicaron a la elocuencia, no perseveran ya en su ser ni en el esplendor del foro, sino que pasaron primeramente a los pórticos y academias y después a las escuelas públicas, y los maestros de la elocuencia no enseñan lo que se requiere para formar un orador, es necesario verdaderamente aprender de aquellos entre quienes quedó (Quintiliano, 302).

Intuimos la crítica a la línea contemplativa Platón-Cicerón y el beneplácito del bilemorfismo aristotélico por la relación del concepto de potencia al servicio de la noción de arte. Siempre con el objetivo de legitimar la superestructura educativa del aparato imperial, como también podemos observar en su valoración del resto de movimientos existencialistas: «Porque Epicuro por sí mismo nos aparta de su filosofía pues dice que se huya de toda ciencia con el mayor conato que se pueda» (Quintiliano, 306).

Vislumbrado el «qué» de Quintiliano nos queda el «cómo», que sin duda es la mayor parte de sus Instituciones Oratorias, y que podemos puntualizar para preparar el espacio de génesis del naturalismo y así engarzar el concepto de Modernidad en el Renacimiento:

- La educación regulada por las exigencias de la naturaleza humana a la que aspira perfeccionar.

- La Naturaleza se selecciona con bondad y firmeza y genera cinturones de herrumbre de incapaces, lo cual explicará más adelante el concepto de fracaso escolar como estrategia intrasistémica.

- El arte no es el efecto sino la causa, la relación arte-naturaleza no es dialógica sino de prevalencia, siendo adecuada para el Imperio, la doctrina y el dogma para un Arte instrumental mucho más efectiva que una Naturaleza en constante cuestionamiento de sí misma.

- La disociación antropología-sociología a favor de la última explica la urgencia de la instrucción para acelerar el proceso y responder al crecimiento del Imperio. Prevalece una imitación que precipite el proceso de socialización 
del futuro administrador del imperio (apparitores). La táctica educativa será la didáctica.

- El hombre es bueno por naturaleza, por lo que lo natural en educación es la bondad. De ahí que asociemos la «blandura» teórico-pedagógica al $\mathrm{Na}$ turalismo.

- La techné -que finalmente depende del sentido común- representa diacrónicamente el concepto de Humanitas o Paideia y cuyo fin es la supervivencia del Imperio. Aquellos que no poseen la techné requerida y obtenida a través de la instrucción son bárbaros o esclavos.

- La memoria como capacidad y la imitación como método junto a la multidisciplinariedad y el juego son las tácticas para la docilización del discípulo.

- La búsqueda de una armonía a través de la educación en un contexto inarmónico es la pauta que explica cómo el Naturalismo coyuntural se estructura.

¿Por qué Quintiliano desaparece al modo del Guadiana durante toda la Edad Media? Tal vez, porque el pensamiento que sintetiza su obra dota de tal importancia a la Naturaleza, alejándola simultáneamente del valor del azar, que recubre al individuo de una inmanencia estoica contraria estéticamente a las reflexiones agustinianas.

Los siglos v y vi, vitales para alejar al Medievo de lo tenebroso, aclaran a través del pensamiento de Agustín de Hipona, Berceo y san Benito, no solo el devenir del largo tiempo feudal, sino por qué la trascendente Metanoia cristiana -también dogmática y reproductiva- va a establecer el antagonismo con el hispano-romano en el valor divino que le otorgará al medio ambiente.

Sin embargo, ese largo silencio va a construir lentamente (a través de las grietas que ampliarán como campo de batalla el pensamiento judeo-arábigo) un espacio catedralicio -a modo de nueva ágora-; espacio en el que Tomás de Aquino aggiornamenta el sistema tradicional de enseñanza -lo escolastiza respecto a los valores feudales y monacales de la Alta Edad Media- como un ejercicio de secularización e intento de racionalización de la tradición.

Entre vértebras, la Baja Edad Media, con la reapertura -como en el helenismo o en el Imperio- de las rutas comerciales y la expansión del mundo conocido, insinúa los neoclásicos pilares del Renacimiento por venir: la tabula rasa de los estoicos, la potencia aristotélica y la memoria de Quintiliano -como serpiente ourobouro- anuncian aciagamente un período donde se dan los primeros pasos de un capitalismo que ya en el quattrocento será imparable.

Tomás de Aquino, dentro de la controversia escolástica, la urbanización y el nacimiento de las universidades europeas, va a dar idéntica respuesta al valor de la naturaleza que el hispano-romano. Posteriormente, el Renacimiento tendrá en Michel de Montaigne el ensayo crítico que mostrará el callejón sin salida al que llevan los procesos naturalizados y su facilidad para auxiliar sistemas totalitarios de unificación.

Observemos las siguientes características del Renacimiento y establezcamos analogías con el Imperio de Quintiliano, a fin de entender, las razones de su rescate para la salida triunfal -y nuevamente ecuménica- de los sistemas esclavistas de producción ahora convertidos en manufactura mercantilista: 
IN-COMPETENCIAS DE LA UNIVERSIDAD OCCI-NEO-LIBERAL. DE LOS SUEÑOS DE QUINTILIANO A LAS PESADILLAS DE MICHEL DE MONTAIGNE

ANDRÉS GONZÁLEZ-NOVOA

- El hombre del Renacimiento es absoluto, autónomo y libre, individuo hedonista en un mundo que se aleja de la trascendencia para potenciar una inmanencia productiva.

- El objetivo o misión vital de este gentilhombre es el éxito y promoción dentro de una sociedad a la que engañar (Maquiavelo), robar (Giordano Bruno) o mentir (Campanella).

- La perfeccionable naturaleza -que ya era bella en sí- es «un conjunto de entes objeto de la experiencia, regidos y determinados por leyes naturales», (Belenguer Calpe, 33).

- La naturaleza es para el Renacimiento una musa y una esclava del arte del hombre.

- La afirmación de Occam de que los conocimientos son intuitivos (Empirismo y Racionalismo) instaura un saber inmanente antagónico a las visiones de trascendencia (gnoseológica y ontológica).

- El origen del Estado Moderno se afirma frente a los poderes exteriores e intermedios para el monopolio interior y su extensión a través del ejército y el patriotismo.

- Una nueva clase social, la burguesía, eclosiona con la ampliación del mundo conocido a través de la conquista de África y América, la instauración del Imperio Sacro Germano y la extensión del pensamiento protestante al servicio del emergente capitalismo.

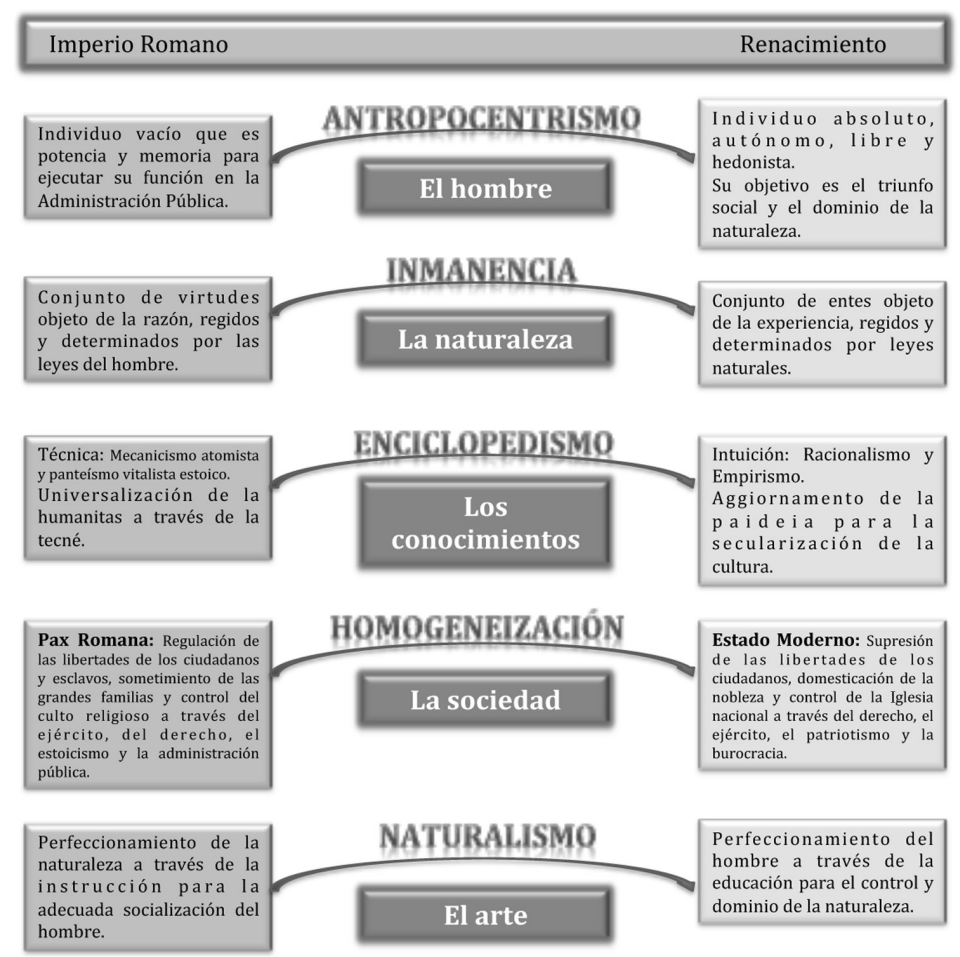


IN-COMPETENCIAS DE LA UNIVERSIDAD OCCI-NEO-LIBERAL. DE LOS SUEÑOS DE QUINTILIANO A LAS PESADILLAS DE MICHEL DE MONTAIGNE

ANDRÉS GONZÁLEZ-NOVOA

Es importante entender que la obra de Quintiliano está sujeta infraestructuralmente a la clase que pertenece; supone, al mismo tiempo, una sutil crítica y una oportunidad de ocupar el nuevo campo vacío administrativo que generan las conquistas sobre los bárbaros. Ese nuevo espacio exige, para su gestión, de un aparato burocrático complejo, un sistema educativo público que capacite y especialice mecánicamente a los apparitores.

Ese sistema público de instrucción, pergeñado en las Instituciones Oratorias, va a socializar adecuadamente, desde de un modelo de arte técnico, a los futuros ciudadanos, a través de una pedagogía «blanda» que, tácticamente, entiende la naturaleza humana (bondadosa y moldeable), adecuada para una eficaz segregación laboral. Por lo tanto, la educación, procedente de la semilla pre-naturalista, es un proceso de secularización, síntesis y compilación de la bumanitas para la inmanencia del individuo y su fidelización a un Estado totalitario.

El Renacimiento, ese largo trayecto también de secularización de la cultura que tiene su génesis en la Baja Edad Media, que afirma con Occam y es favorecido por la caída de las líneas arancelarias y las nuevas conquistas en América y África tendrá, sin duda, elementos que posibilitarán su retorno.

El afortunado hallazgo de Poggio Bracciolini (I386-I459) del texto completo de las Instituciones Oratorias (Ross, I878) y la estructuración de los Estados modernos para la inminente llegada del Imperio de Carlos V volverán a configurar un modelo educativo basado en el naturalismo y propiciarán una reacción en el seno del Sistema Escolástico de Enseñanza a través de la Compañía de Jesús.

Dichos contextos seleccionarán para su extensión, rápida y violenta, un modelo antropocentrista, darán valor inmanente a la Naturaleza, primarán el conocimiento enciclopédico y será vital, tanto en la estructura como en la superestructura, lo técnico. Todo ello para la osamentación de regímenes autocráticos.

Quintiliano va a renacer en el proceso escolástico a través de Tomás de Aquino, va a idealizarse en el trecento con Dante Alighieri, Petrarca y Giovanni Bocaccio, sintetizarse en el Quattrocento con Petrus Paulus Vergerius y va ser cuestionado profundamente por Michel de Montaigne en la Francia tardohumanista (Bowen, 1997). Diacrónicamente y con un bamboleo preocupante avanzará entre la matriz jesuítico-comeniana y el liberalismo roussoniano.

Es el origen calvinista del capitalismo, en un período de prepotencia respecto a la naturaleza, de expansión del mundo conocido y de crecimiento de las oportunidades comerciales; un tiempo de esplendor público, de un arte al servicio de los mecenas, del resurgir de las filosofías individualistas y del florecimiento de las universidades, las bibliotecas y los museos. Dicha euforia, ingenua o irresponsable, será el leitmotiv de la crítica honesta del callejón sin salida que muestra Michel de Montaigne. En sí, el francés desnuda ensayo a ensayo a una globalización des-humanizada (producto de un proyecto humanístico agotado), que parece fundamentada en la barbarie naturalizada de un lenguaje políticamente correcto y establecida fuertemente a través de un pensamiento dogmático.

Los ensayos nos explicarán cómo entiende que tanto Quintiliano como el Quattrocento van a promocionar un modelo antropológico de siervo instruido. Esta estrategia va a generar una sociedad paternalista bajo estandartes democráticos por medio de unos sistemas educativos preparados para infantilizar al 
IN-COMPETENCIAS DE LA UNIVERSIDAD OCCI-NEO-LIBERAL. DE LOS SUEÑOS DE QUINTILIANO A LAS PESADILLAS DE MICHEL DE MONTAIGNE

ANDRÉS GONZÁLEZ-NOVOA

ciudadano y someterlo. La pregunta inferida queda así formulada: ¿cómo se va a perfeccionar el mundo y la sociedad si el ciudadano no se perfecciona a pesar del mundo y la sociedad?

\section{Michel de Montaigne y la Universidad de espaldas al conocimiento}

De los diferentes (en magnitud) proyectos de globalización que ha sufrido la memoria civilizatoria, tras el ensayo helenístico, nos ocupa, por motivos o razones que explicitaremos, aproximar la mirada al Imperio romano, no como cúspide sino como origen de nuestras sospechas.

Muy lejos de una memoria pagada con oro por emperadores y senadores, alejados de los idealizados relatos de Juvenal, Suetonio, Tácito o Plutarco, la Roma real que va a cristianizar el Renacimiento era un sueño de patricios que, habitando la gran urbe, sostenían su gloria sobre la miseria de casi dos millones de almas que in-habitaban las catacumbas.

En el momento de las grietas, lejos de pensar en reconstruir el edificio o repensar en otro modelo de convivencia, pagaron a los mercenarios y los permitieron vivir dentro de la ciudad como el primer cuerpo de represión urbana.

Ya lo insinuaba, sin embargo, el verso de Novalis, largas sombras pueden ser proyectadas por pigmeos. Esas mismas sombras son las que detecta Michel de Montaigne desde la atalaya del ensayo. El Renacimiento como nuevo intento de globalización se sustenta en un modelo de cultura hegemónica instalada en un proyecto de Universidad pantagruélica.

Si ponemos asunto a la prudencia de Sancho Panza, a su sencillez y a su límpido mirar, en esa gran explanada, esbozada en la Declaración de la Sorbona de I998, lejos de una magna ingeniería epistemológica, intuimos ligeros trazos a carboncillo sobre la movilidad (filtro maquiavélico a las migraciones), el empleo y una ambigua relación entre interés nacional y deseos personales.

El recelo sobre una razón económica instalada en el seno de la cultura no es insólito, en realidad, tal sospecha forma parte de todo espíritu de resistencia contra la uniformización del pensamiento.

Haciendo de la memoria experiencia, compartiendo acontecimientos con los otros amigos en el tiempo, hallamos en el ciclo pedagógico entre Quintiliano y Michel de Montaigne el proyecto y la crítica de un proceso de uniformización de la cultura que conecta, por filias y también por fobias, el Imperio romano con el Renacimiento y éste con nuestros días.

En ambas acotaciones de la nostalgia se nos revelan con nitidez procesos esenciales para desvelar un complejo divorcio entre la tradición y el progreso. El antropocentrismo que entra en escena con el Imperio, comienza con el modelo de individuo vacío: memoria y potencia al servicio de la administración pública, para aterrizar como ente absoluto, libre y hedonista en el Renacimiento.

En tales períodos, la inmanencia da primacía objetiva a las leyes del hombre, las cuales emanan de la experiencia que resulta de la observación y el estudio de las leyes naturales. Caen dioses, también lo fantástico. 
IN-COMPETENCIAS DE LA UNIVERSIDAD OCCI-NEO-LIBERAL. DE LOS SUEÑOS DE QUINTILIANO A LAS PESADILLAS DE MICHEL DE MONTAIGNE

ANDRÉS GONZÁLEZ-NOVOA

Tanto la Pax Romana como el Estado Moderno son proyectos homogeneizadores que parten de un derecho naturalizado, es decir, divinizado por el naturalismo.

El conocimiento que requiere tal proyecto de sociedad y tal modelo de individuo es enciclopédico, técnico, es la universalización de la bumanitas a través de la techné. Lo que en principio hiciera el mecanicismo atomista bajo togas panteístas, lo hiciese el Quattrocento mediante racionalismo y empirismo, aggiornamentando la Paideia.

Lo que intenta advertir esta breve analogía civilizatoria y occidental, la sinrazón del ensayo y el escepticismo que rezuma es que la crítica que revelan los escritos de Michel de Montaigne, el esperpento que habita en el gigante de Rabelais, también lo que se esconde en la abadía de Thelemé, son vitales para comprender que la siguiente Declaración de Bolonia de 1999, con su sistema de titulaciones, sus ECTS (European Credit Transfer System), los criterios mesológicos comparables y la cooperación en el desarrollo curricular con el mundo empresarial, no solo aniquilaba su primer espíritu, sino que nos recordaba con frescura el sonado fracaso de los Studium Generale Universitas del Renacimiento y la perversión que ocultaban sus afamados studia bumanitatis.

Es curiosa la historia y las maneras que tiene de proyectarse como presente. Es sombra de pasiones y fulgor de baratijas, es siniestra y generosa, es mundial aunque con frecuentes ataques de anorexia occidental. Y aunque parezca el producto de las sombras chinescas de la caverna de Platón, no deja de contarnos, a la vez, lo que pasa al otro lado del muro. Claro que utiliza otras palabras, busca otros lectores.

En el caso del Renacimiento, tras el esplendor inapelable de su arte y la contundencia lapidaria de sus cuchillos palaciegos, encontramos profundas grietas en el modelo cultural occidental, a pesar del ilusionante proyecto de apertura que encarnaron los grandes nombres del Trecento. Esa doliente derrota, con la distancia prudente del kronos y bajo el auspicio de un kairos comprensivo, fue para el Renacimiento lo que para nosotros hoy el primer espíritu de Bolonia, el aliento que pretendemos devolver al escenario, con la convicción de que una Universidad de espaldas a la producción de saberes es una fábrica del siglo xxI.

Perseguimos el espíritu y los sueños que encarnaron los Dante, Petrarca y Bocaccio frente a los que habrían de mercantilizar, al peso, los frutos de la cultura.

Los tres del Trecento imaginan un hombre en posición intermedia entre razón y espíritu. Dibujan al sfumato un antropocentrismo vitrubiano inspirado por una tradición literaria que re-escrituriza la nostalgia como un ejercicio intelectual y cultural. Un hombre desenfocado, sin corsé ni amalgama, un hombre capaz del arte de la instalación (Sloterdijk, 2007) en un mundo que parece capaz de modernizarse sin sus habitantes.

Pero la otra historia, la que graba sus símbolos en fuego y hierro, nos revela la perversión intrasistémica que aniquila los esfuerzos de Maquiavelo y Bocaccio, una tradición traicionada. La educación de un gentilhombre consumada desde la instrumentalización de los studia bumanitatis de $1430^{8}$.

8 La expresión studia humanitatis fue contrapuesta por Coluccio Salutati a los estudios teológicos y escolásticos cuando tuvo que hablar de las inclinaciones intelectuales de su amigo Francesco Petrarca; en éste, humanitas significaba propiamente lo que el término griego filantropía, 


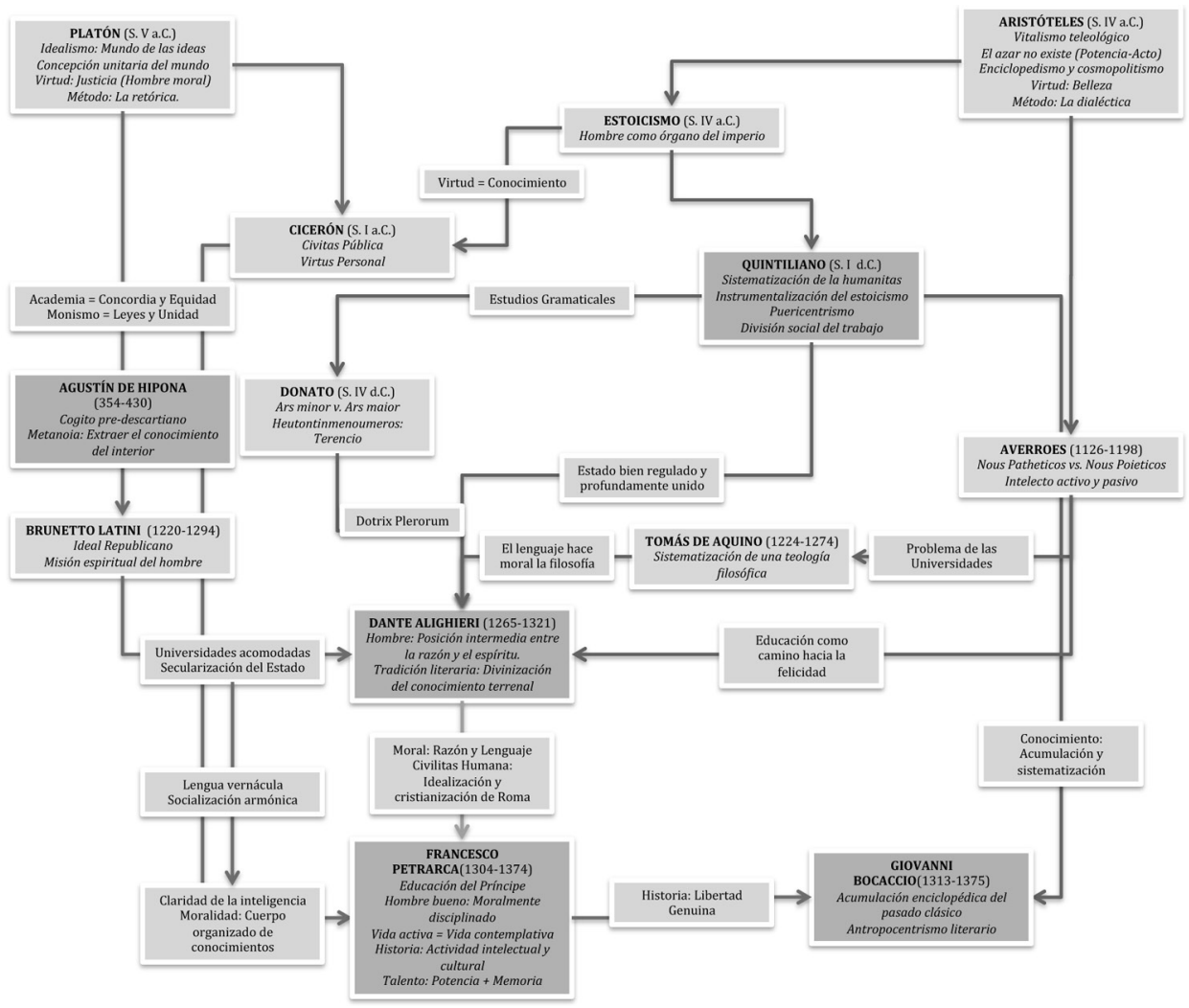

Esta línea escolástica de enseñanza, revitalizada por el antropocentrismo literario y con tintes de enseñanza activa aristotélicos, llegará a inspirar el programa educativo del humanismo de Petrus Paulus Vergerius9 (I349-I420).

amor hacia nuestros semejantes, pero en él el término estaba rigurosamente unido a las litterae o estudio de las letras clásicas.

9 «Llamamos a los estudios liberales, que son dignos de un hombre libre, los estudios, en que podemos lograr y practicar la virtud y la sabiduría que la educación suscita, entrena y desarrolla los más altos dones de cuerpo y mente de los hombres que ennoblecen, y que con razón considera siguiente rango en la dignidad de la virtud. Para obtener una ganancia, carácter sencillo y placer son el único objetivo de la existencia, a una naturaleza noble, valor moral y reputación. Es, pues, de suma importancia que, incluso desde la infancia este objetivo, este esfuerzo, constantemente debe mantenerse vivo en la mente progresivamente. Porque se puede afirmar con plena convicción de que no haya cumplido la sabiduría de nuestros años más tarde, a menos que en los primeros hayan entrado con sinceridad en su búsqueda Tampoco podemos admitir por un momento, como la mayoría piensa, que aquellos que prometen primero fracasan en el cumplimiento posterior. Esto puede deberse, en parte, por causas físicas, suceder en casos excepcionales. Pero no hay duda de que la naturaleza ha dotado a algunos niños con tantas ganas, tan dispuesta una inteligencia, que sin esfuerzo tendrían que alcanzar un notable poder de razonamiento y conversar sobre temas graves y elevados, y con la ayuda de la guía correcta llegar al sonido, en la edad adulta, de la más alta distinción», Vergerius, P. P.: De ingenuis moribus ac liberalibus studiis en Artola, M.: Textos fundamentales para la historia, Madrid, Alianza Editorial S.A., I992, pp. 175-176. 
IN-COMPETENCIAS DE LA UNIVERSIDAD OCCI-NEO-LIBERAL. DE LOS SUEÑOS DE QUINTILIANO A LAS PESADILLAS DE MICHEL DE MONTAIGNE

ANDRÉS GONZÁLEZ-NOVOA

En el establecimiento de los studia humanitatis (artes pasivas y liberales) y su extensión, a través de los estudios generales de las universidades, tenemos el cuerpo educativo que va a concentrar en el concepto de gentilhombre los principios didácticos de Quintiliano -transformados por Baltasar Castiglione (I478-I529)para diseñar un modelo de ciudadanía que, a través de la descontextualizada lectura de Platón y Cicerón, transforme la civitas en lealtad al príncipe. Así, Juan Colet extrae la vida activa como fundamento mesológico para el comportamiento sumiso en sociedad, y se torna en precedente de lo que se establecerá en el Romanticismo como Escuela Activa.

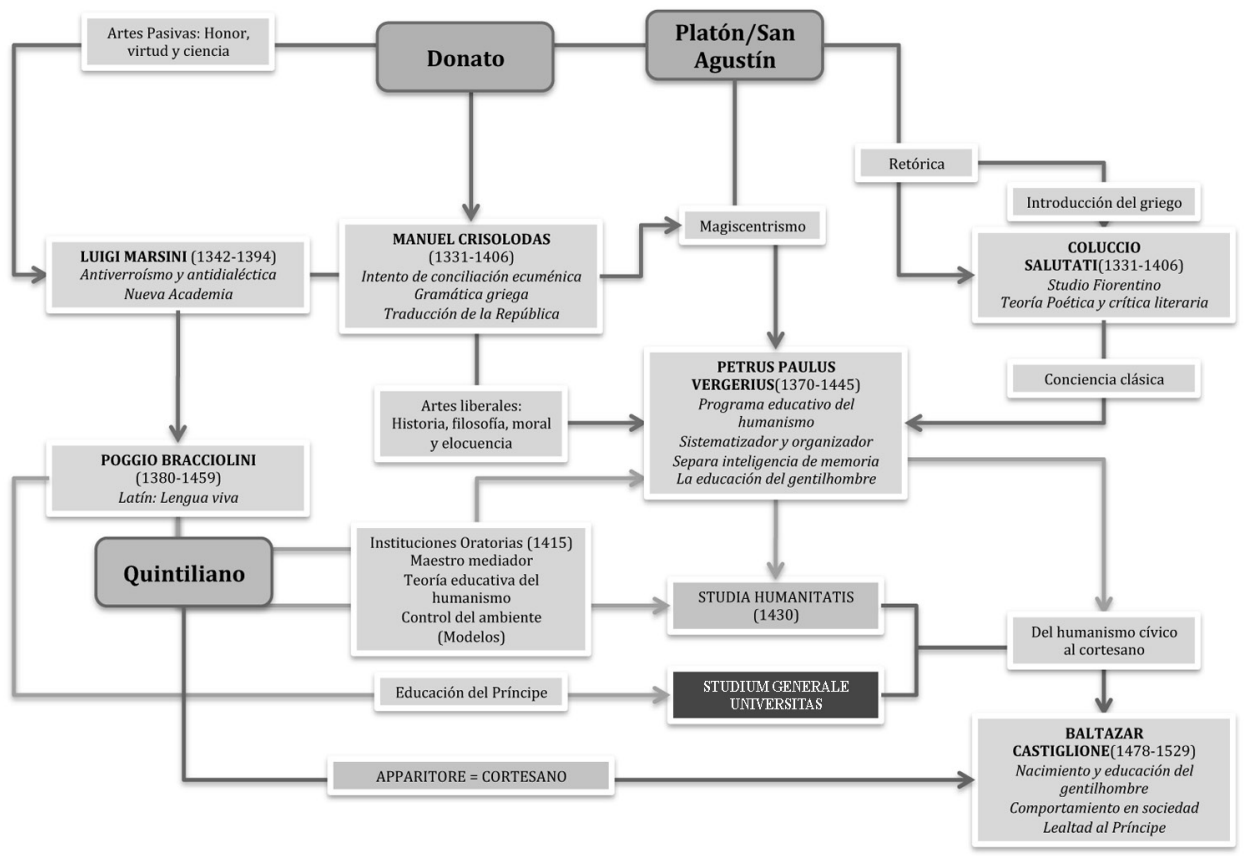

Tal horizonte, contemplado desde la silenciosa soledad de su castillo, conforma el pre-texto para que Michel de Montaigne nos permita volver la mirada a la explanada, y sospechar profundamente de las bondades del proyecto de Universidad bursátil y, por lo tanto, intuir las múltiples imposibilidades por las cuales no podrá producir conocimiento:

- Michel de Montaigne, en su crítica a los studia bumanitatis, percibe lo educativo como un proceso tolerante, de relativismo cultural, un templo sin muros que aloja cualquier experiencia que, habiendo saciado su sed en el pozo de la tradición, se preste a producir conocimiento. Lo que actualmente Boaventura do Santos acierta a definir como las epistemologías del sur o la ecología del saber.

- El callejón sin salida que vislumbra proviene de un fuerte dogmatismo tradicionalista y epistémico que impide la conciliación entre lo moral y lo político (Maquiavelo), y que torna las leyes que rigen lo comunitario en arbitrarias. 
IN-COMPETENCIAS DE LA UNIVERSIDAD OCCI-NEO-LIBERAL. DE LOS SUEÑOS DE QUINTILIANO A LAS PESADILLAS DE MICHEL DE MONTAIGNE

ANDRÉS GONZÁLEZ-NOVOA

- El valor de la experiencia directa intenta encontrar un justo medio entre el magistrocentrismo (Platón) y el puericentrismo (Quintiliano), para que el maestro escuche al discípulo (Sócrates), generando en el aula un espacio para la crítica a través de la lectura de los clásicos (Petrarca y Tomás Moro), la observación, la reflexión y el diálogo; tornando ésta (la experiencia) en movimiento pedagógico que sólo puede aprovechar la intuición entendida como reflexión intelectual. Por lo tanto, el objetivo fundamental de la educación es el conocimiento de sí mismo (conciencia) del alumno.

- Tras la experiencia del descubrimiento de América, la verdad humanista no tiene sentido; otras culturas desvelan diferentes verdades. Montaigne percibe a través de las lecturas de Plutarco, Horacio, Suetonio y Salustio que el proyecto humanista de Platón y Cicerón (que intentan revitalizar sin éxito los hombres del Renacimiento) ha sido corrompido por una sociedad pervertida política, social, económica y culturalmente.

- Hereda de la trayectoria Sócrates-Erasmo (en la cual Estoicismo, Epicureísmo, Escepticismo y Pesimismo son fundamentales) el concepto de que la filosofía es la disciplina que nos enseña a morir. Integra la inmanencia en un fondo de trascendencia y, frente a la decadencia del proyecto renacentista, ensaya un nihilismo $\mathrm{o}^{\text {To }}$ pedagógico, profundamente naturalista, en la búsqueda de una tradición ético-política.

El callejón sin salida es inicialmente epistemológico y se puede asociar a la afirmación goyesca: «Los sueños de la razón producen monstruos». La crítica al exceso de razón y a la naturaleza del conocimiento pre-empírico (fundamentalmente estratégica) la aprehendemos desde el rechazo al cuantitativo enciclopedismo que hereda de la línea Aristóteles-Averroes-Bocaccio. El espejo de dicha perversión epistemológica se refleja con claridad en la Abadía de Théleme ${ }^{\text {II }}$ que esculpe grotescamente Rabelais a través de un humanismo que se atiborra, extiende y regula, en forma de studium generale, en el seno de las recién bautizadas universitas.

Dicha sistematización acumulativa del conocimiento (sin procesar) favorece el concepto de memoria que se desprende de Quintiliano, una episteme promocionada por el lema «alma inflada, no llena» y que se enfrenta o dificulta el olvido y el perdón (Cicerón) para la configuración del entendimiento como explicitación de la conciencia. La falsa inmanencia que percibe del estoicismo humanista es entendida como dogmatismo y anacronismo frente al principio de incertidumbre

1o Es preciso aclarar que el término Nihilismo surge en la literatura de Turgeniev, pero a través de la actitud de conformar la naturaleza humana desde la insignificancia frente a una revitalizada naturaleza queda acertadamente nomenclaturizado.

"En I 532 e inspirado en Les grandes et inévitables chroniques de l'enorme geant Gargantua (poema popular que condensa novelas caballerescas del corte de las crónicas artúricas) se escribirá el primero de los cinco libros que van a componer la obra crítica de François Rabelais. Animado por el propio Erasmo incluirá el capítulo de la Abadía en el cual, a través del juego etimológico de la palabra Thélèma que viene del griego voluntad, va a cuestionar el conocimiento humanista por abocar estructuralmente en el mismo dogmatismo que ha consolidado las prácticas educativas religiosas y la vida monacal en sí misma. 
emanado del relativizado cristianismo de Erasmo de Rotterdam, desde el cual la virtud, ante la ausencia o exceso de verdades absolutas, requiere de un alma flexible que entienda la inteligencia ligada a los humores del hombre.

Tampoco los estoicos pretenden que el alma de su sabio pueda resistir a las primeras visiones y fantasías que le sobrevienen. Por el contrario, como si se tratara de una sujeción natural, le permiten ceder ante el estruendo del cielo o de un derrumbamiento, por ejemplo, hasta la palidez y la contracción. Lo mismo en las demás pasiones, con tal de que su opinión permanezca libre e intacta, y de que la sede de su razón no se vea alcanzada ni alterada en modo alguno, y con tal de que no consienta en su terror y sufrimiento. En cuanto al que no es sabio, sostienen lo mismo con respecto a la primera parte, pero cosa muy distinta con respecto a la segunda. Porque la impresión de las pasiones no es en él superficial, sino que penetra hasta la sede de la razón, infectándola y corrompiéndola. Juzga según ellas y se acomoda a ellas. Ved, muy elocuentemente y plenamente, el estado del sabio estoico: Mens immota manet; lacrymae volvuntur inanes (Montaigne, 2007: 64-65).

Tal presentimiento a finales del Renacimiento, el eco de tamañas empresas y los esbozos de lo que se nos viene recrudecen el escepticismo, el pesimismo y el nihilismo que también acompañan este ensayo.

La osamenta positivista que origina y condiciona la escala de los ECTs, las ponderaciones de la ANECA, las mediciones de impacto JRC o las valoraciones del informe PISA, la conversión del profesor universitario en un burócrata con tintes de gestor ocupacional, la búsqueda de una cualificación profesional adecuada y la mutación del concepto de cultura en competencias nos devuelven la mirada a otro callejón sin salida, en el que nuevamente, y sin remedio aparente, lejos de abordar un proyecto educativo trans-cultural, coronamos el proceso largo y asfixiante de mercantilización de la cultura mediante la transformación de las universidades en laboratorios empresariales trasnacionales.

Asumiendo la dificultad que supone comparar momentos históricos neológicamente diferenciados, encontramos, en el proceso encarnado por Quintiliano y en la crítica de Montaigne, patrones que nos permiten analizar y sospechar del Espacio Superior de Educación Europeo, emanado de los principios diseñados por economistas en el Consenso de Washington y concretados en la ansiada sociedad de la información del Tratado de Lisboa.

Primeramente, delimitar un espacio educativo es una contradicción que rompe con la idea de universalidad de la propia Universidad, hay más mundo y más culturas dentro y fuera de Europa.

Además, es curioso cómo se asume el concepto «Educación Superior» y se concibe la Universidad como una etapa aislada, preocupante cuando esa superioridad es inferida por criterios empresariales de competencia que encubren estrategias de división social del trabajo. Un ejemplo clarificador es lo sucedido en los años 80 bajo el ministerio de Cox, cuando bajo la semántica técnico-liberal y en defensa de una educación de calidad aplica los términos libertad, clientelismo, eficacia, productividad y rendimiento como pilares de una educación democrática.

La trampa, ya urdida por Quintiliano en Roma, se explica sencillamente desde un ejemplo. Pongamos que tenemos diez universidades con capacidad para mil 
IN-COMPETENCIAS DE LA UNIVERSIDAD OCCI-NEO-LIBERAL. DE LOS SUEÑOS DE QUINTILIANO A LAS PESADILLAS DE MICHEL DE MONTAIGNE

ANDRÉS GONZÁLEZ-NOVOA

alumnos cada una. Unas privadas, otras públicas, ambas evaluadas por agencias externas con criterios objetivos unidimensionales. Imaginemos que somos libres de elegir la que recibe la mayor valoración, la que se presume que ofrece mejor educación o educación de calidad. Solo mil podrán elegir esa Universidad, los otros nueve mil tendrán que luchar por las otras nueve universidades. De esta manera, la Universidad más valorada podrá aplicar criterios, nuevamente objetivos, de rendimiento escolar y conformará un alumnado homogéneo basado en criterios académicos. Obviamente podemos imaginar el alumnado que terminará en la Universidad peor valorada (Viñao Frago, 1999).

Lo que vamos dibujando en un sistema en el que, finalmente, tendremos universidades claramente marcadas por comunidades educativas homogéneas en base a patrones socio-económicos.

Pero sigamos. En España tenemos casi cien mil profesores universitarios que son evaluados por expertos en educación. ¿Quiénes son esos expertos y qué los acredita como tales? ¿Acaso los profesores universitarios no son expertos en educación?

El EeEs pone un especial énfasis en la planificación basada en las competencias, un énfasis que recuerda a los principios puericentristas de Quintiliano que con tanto énfasis criticó Montaigne. Por un lado, se habla de dignificar y dotar al magisterio de recursos para mejorar y desarrollar hacia la excelencia su docencia y, por otro lado, se centra todo el proceso de planificación en el aprendizaje de los alumnos. Un aprendizaje que debe ser significativo, lo que se traduce intuitivamente en un ajuste a los perfiles laborales que ofrece el mercado de trabajo.

La educación es autoeducación (Gadamer), la autoeducación es formación, la formación es transformación, la transformación es evolución personal: incremento de conciencia y disminución de egocentrismo (infantilismo adulto). La formación es eje y es vector. El aprendizaje significativo no tiene norte, como tampoco lo tienen constructos como la creatividad o la autoestima (Herrán, 2007: Io).

Además, el árbol de las competencias parece un cactus positivista que bien recuerda al enciclopedismo pantagruélico que denuncia Rabelais. Competencias fundacionales, laborales, profesionales, investigativas, didácticas, pedagógicas y tecnológicas que no incluyen competencias expresivas, de razonamiento, de búsqueda y selección de información, de relaciones interpersonales (capacidad de comunicación, trabajo en equipo, liderazgo, aprendizaje de los compañeros del propio u otros departamentos, discreción, contribución a un clima positivo, mediación y resolución de conflictos...), organizativas (planificación de proyectos, gestión de la comunicación, organización personal para el desarrollo de responsabilidades y cargos, organización para la resolución de problemas organizativos, evaluación de sistemas y procesos...) y éticas (sentido crítico, autocrítica y rectificación, responsabilidad, coherencia, solidaridad, sentimiento de justicia, respeto por el medio ambiente...) (Herrán, 2007).

Competencias vacías y banales que no incluyen autoconciencia histórica ni señas dinámicas de cambio para su vinculación al futuro deseable. Propias de un utilitarismo que aleja el espíritu de la Universidad de la forja de caracteres 
IN-COMPETENCIAS DE LA UNIVERSIDAD OCCI-NEO-LIBERAL. DE LOS SUEÑOS DE QUINTILIANO A LAS PESADILLAS DE MICHEL DE MONTAIGNE

ANDRÉS GONZÁLEZ-NOVOA

y espíritus capaces de hacer uso crítico de la información y que reniega de la máxima de Montaigne de las cabezas bien hechas frente a las cabezas hechas a la medida del yugo que les corresponda.

Otro aspecto vinculado a las competencias deviene en una profunda contradicción. Si bien se percibía, desde Bolonia, que las Universidades funcionaban en base a los deseos de sus facultades y de sus departamentos y eso las «guetizaba», la política de incentivos y la obligatoriedad investigadora habrán de generar una especie de circo docente en el que unos lucharán contra otros por los sagrados sexenios y, por otro lado, que, en base a los criterios JRC y las propias estructuras de poder científico, la investigación por decreto obligará al profesorado a asociarse y generar conocimiento acumulativo, al modo del enciclopedismo, que sature la comunidad educativa sin promover avances convivenciales en la sociedad.

Los propios indicadores de citaciones recuerdan a Wittgenstein en las palabras de Cervantes: «buscando autores que digan lo que yo me sé decir sin ellos». Precisamos de observar la cantidad de artículos idénticos que se citan entre ellos para comprender que tales estructuras de cualificación del conocimiento premian, como anheló Quintiliano, a la nueva clase de apparittores, amantes de la burocracia y adictos a participar en congresos y simposios como pretextos lúdicoturísticos. Se imponen como un nuevo paraíso los «paper» y los «abstract» frente al ensayo.

Se premia la novedad, como en el periodismo de esta realidad virtual globalizada, un conocimiento «mcdonalizado» (Moreno, 20Io) que prioriza la potencia aristotélica de ser convertido en tecnología comercial, sin dar una sola concesión al conocimiento que tenga valor humano. Por eso se pone fe y alma en las TIC con la esperanza de que aniquilen el último obstáculo de la estulticia humana; el profesorado y las aulas.

Bien lo reflejó Paulo Freire y la situación, bajo la calidad de la in-competencia, ofrece un panorama que dista mucho de la excelencia. La ultrarrealidad universitaria supone la desintegración de la sustancia simbólica (Baudrillard, 2004) para diseñar, como dédalos, un gran laberinto cognitivo de perfección técnica, una especie de genética de la estandarización capaz de clonar, desde el jeroglífico de la mercancía y bajo la seña del tiempo virtual (inmerso, inmanente, inmediato), un serial morphing de universidades soñado por Quintiliano y desvelado, desde los ensayos, por Michel de Montaigne.

\section{Bibliografía}

ApPadurai, A.: El rechazo de las minorías. Ensayo sobre la geografía de la furia, Barcelona, Tusquets Editores S.A., 2007.

Artola, M.: Textos Fundamentales para la Historia, Madrid, Alianza Editorial s.A., 1985. Baudrillard, J.: El pacto de la lucidez. El imperio del mal, Madrid, Amorrortu Editores S.A., 2004.

BAYLY, C. A.: El nacimiento del mundo moderno I780-I9I4, Madrid, Siglo XXI de España Editores S.A., 2004.

Belenguer Calpe, E.: El naturalismo pedagógico, Madrid, Editorial Síntesis s.L., 2004. 
IN-COMPETENCIAS DE LA UNIVERSIDAD OCCI-NEO-LIBERAL. DE LOS SUEÑOS

DE QUINTILIANO A LAS PESADILLAS DE MICHEL DE MONTAIGNE

ANDRÉS GONZÁLEZ-NOVOA

Bowen, J.: Historia de la educación occidental, Barcelona, Herder, 1997.

Do SAnTos, B.: Una Epistemología del Sur. La reinvención del conocimiento y la emancipación social, Buenos aires, Siglo XxI editores, 2009.

González-NovoA, A.: Diálogos: tradición y modernidad. (Apuesta por una pedagogía posibilitadora), San Cristóbal de La Laguna, Servicio de Publicaciones de la ULL, 2013.

Herrán, A.: «Después de Bolonia», Educación y Futuro, Madrid, Ces El Bosco, n. ${ }^{\circ}$ i6 (2007).

Jaeger, W.: Paideia, Madrid, Fondo de Cultura Económica de España s.L., 2004.

Montaigne, M.: Les Essais (Los Ensayos según la edición de I595 de Marie de Gournay), Barcelona, Ediciones Acantilado, 2007.

Moreno Moreno, P.: La política educativa en la Globalización, México, Universidad Pedagógica Nacional, 20 Io.

Ponce, A.: Educación y lucha de clases, Madrid, Ediciones Akal s.L., I987.

Quintiliano, M. F.: Instituciones Oratorias, traducción directa del latín por los padres de las Escuelas Pías Ignacio Rodríguez y Pedro Sandier, tomos I y II, Madrid, Imprenta de Perlado Páez y Compañía, I9I6.

Ross, J. W.: Tacitus and Bracciolini. The Annals Forged in the $X V^{\text {th }}$ Century, London, Project Gutenberg EBook, 1878 .

Sloterdijk, P.: En el mundo interior del capital. Para una teoría filosófica de la globalización, Madrid, Ediciones Siruela s.A., 2007.

Smith, A.: La riqueza de las naciones, Madrid, Alianza Editorial s.A., 20oI.

Toynbee, A.: Historia de las civilizaciones, Madrid, Editorial Labor s.A. y Alianza Editorial S.A., 1998.

Vidal Araya, L.: «Aproximación deconstructiva a la noción de Calidad de la Educación en el contexto latinoamericano», Revista Iberoamericana de Educación, n. ${ }^{\circ}$ 44/4 (2007).

Viñao Frago, A.: «El concepto neoliberal de calidad de la enseñanza: Su aplicación en España (1996-1999)», Revista Electrónica Escuela Pública, n. 2 (1999).

Wallerstein, I.: Análisis de Sistemas-Mundo, Madrid, Siglo xxi Editores, 201 . 